\title{
Face Management and Issues of Power, Solidarity, and Distance: Socio-Pragmatic Influences on Literary Discourses
}

\author{
V. Vinod Kumar, Vijay Singh Thakur \& Justin James \\ vinod@bdu.ac.in,vijay_thakur@du.edu.om,justin.james@nct.edu.om \\ Department of English, Bharathidasan University, India; \\ College of Arts and Applied Sciences, Dhofar University, Sultanate of Oman; \\ Nizwa College of Technology, Sultanate of Oman.
}

\begin{abstract}
Literature, in many ways, reflects human societies. Literature is mainly a linguistic and aesthetic reflection of how human beings conduct their personal and social lives. The use of language by nature is a social activity. Human beings conduct all aspects of their lives through language. In the backdrop of this premise, human communication is, by nature, social communication. Furthermore, language is shaped by societies and, in turn, societies are also shaped by the language they shape. The human communication functions and works on the social aspects related to who speaks to whom, when, in what language, where, how, and for what purpose. In all contexts, the sociolinguistic aspects of power principle, solidarity principle, distance, and face management play an influential role in determining the tenor, tone and mode of communication. This paper attempts to examine, analyze and discuss the socio-pragmatic perspectives that shape, guide, and give direction to inter-personal human communication. This analytical discussion of the socio-pragmatic aspects of language use will be carried out through sociolinguistic analyses of dialogic discourses from the magnum opus A Suitable Boy (ASB) authored by Vikram Seth, which is considered to be an authentic socio-cultural document of India.
\end{abstract}

Keywords: face management, power principle, socio-pragmatic influences, solidarity principle

\section{Introduction}

Linguistics, literature, and human communication have been gravitating towards each other for a long time in order to develop and build meaningful communicative routes. This paper primarily aims at studying how context-bound discursive discourse practices involve operations of power, solidarity, and face management to construct or deconstruct a variety of identities. Such an analytical process of literary texts sensitizes and raises our awareness of various discourse patterns in everyday human communication with a view to developing human capacities to examine and judge the inter-personal relationships and human societies carefully based on the personal motifs of characters' and their sociocultural milieus. Incidentally, the use of pragmatic interpretive strategies can afford new insights linked with the nature of literary communication, which are not possible by subjecting it to the traditional structural analysis of literary texts simply because it does not take into account the sociolinguistic aspects that play a pivotal role in shaping the ongoing discourse in human communication.

This paper, planned in a socio-pragmatic analytical framework, is organized and presented in the following four parts: (a) The introductory part sets the tone and tenor of the paper. (b) The second part briefly discusses the review of related studies to serve as a 
theoretical foundation for the analytical discussion initiated and evolved in the paper. (c) The third part is devoted to the sociopragmatic analysis of the dialogic discourses retrieved form $A S B$. (c) The last part focuses on drawing concluding remarks and discussing emerging implications from the analytical discussion and critical interpretations of the findings.

\section{Review of Related Studies}

A scientific approach to textual analysis views the literary text as a carefully crafted and orderly object that contains formal and observable communicative patterns. In this objective approach, the act of close analytical reading of the text becomes the primary focus to understand and appreciate literature and draw inferential chains of interpretation to examine the human connections and relations based on the social principles of solidarity and distance and the principle of power and face management.

The first theoretical framework that lends focus and direction to the analytical discussion in this paper is Critical Discourse Analysis (CDA). CDA, based on the works of Fairclough and Wodak (1997) and Wodak (2000), considers language as a discursive practice and places the primary importance on the context of language use in human communication. CDA is based on the central argument that human discourse is tied with, shaped and reshaped by social structure, which includes social class, relative status of the interlocutors, their age, ethnic identity, gender and their socio-cultural milieu, which constrains and shapes interlocutors' identities, interpersonal relationships, and their knowledge and belief system. CDA, to use Teun and Dijk's (2010) argument, is a type of discourse analytical research that primarily studies the way social power abuse, dominance, and inequality are enacted, reproduced and resisted by the text and talk in the social and political context (p. 352). This framework triggers multiple levels of discussion of the relationship between power, ideologies, and language use as it is concerned with examining written and spoken texts in order to uncover socio-culturally motivated sources of power structures, dominance and inequality, and biases and prejudices. CDA also takes into account how these discursive sources of power are developed, initiated maintained, reproduced and transformed within the parameters of specific social, economic, political and historical contexts. As Fairclough (1993) remarks, CDA also strives to explore how opaque and non-transparent discourse relationships serve as factors involved in securing power and hegemony which lead to power imbalances, social inequalities, undemocratic practice, and other injustices. In this sense, CDA is considered a social science research method, which views discourse and its meaning(s) beyond the level of sentences and involves analyzing, interpreting and critically critiquing social life reflected in the text. The analytical strengths of CDA should not be confined to the realm of research alone but be expanded to the teaching of literary discourses in order to enable the students to get engaged with the texts in evolving a multilevel discussion of the discursive sources of power, dominance, role relationships, identities, ideologies, social practices in order to raise students' awareness of discourse patterns in real life as literary texts are closer to the examples of language in real life use.

The second theoretical model of relevance to this paper is the framework of Identity Construction and Performance (ICP). Against the fixed general notion of identity as a fixed and stable core of self, Watson (2006) claims that identity is "an ongoing performative process in which individuals draw on diverse resources for the construction and presentation of the self (p. 509)". Gumperz and Gumperz (1997) provide an elaborated view on this stating that, "the issues of gender, ethnicity, and class are customarily taken as given parameters and boundaries within which we create our own social identities (p.1)". However, the study of language as interactive discourse demonstrates that these parameters are not constant which could be taken for granted but rather are communicatively constructed. Therefore, in order to understand the issues of identity and how those issues affect and get affected by social, ethnic and political factors requires a better understanding of communicative processes by which they arise. Socio-pragmatic modes of analysis are most suitable for providing a 
proper understanding of the communicative processes.

The third theoretical model directly relevant to the concerns of this paper is the Face Management Theory (FMT). This politeness model is propounded by Brown and Levinson (1987) which is based on Goffman's (1972) concept of face, which is related to each individual's self-esteem that is manifested in public. Every competent member of a society emotionally invests this self-esteem due to its vulnerable nature as the face can be either maintained, enhanced, or lost. Therefore, everyone constantly attends to it as a social principle in interpersonal communications. Thus, everyone's face is mutually protected and maintained in the normal course of communication. Conversely, in cases of face threats people have the right to defend their faces and in doing so they can also threaten the face of other(s) if needed. The face involves two aspects: (a) Positive face is related to the positive face wants of being accepted, liked, approved of by others. (b) Negative face is related to the negative face wants of being given freedom from imposition, freedom of choice, and freedom of options by others. Every human being creates or builds a public selfimage or face in accordance with the facerelated norms approved by his/her society. Thus, Goffman (1972) rightly argues that the concept of 'self' is an interactive social construct. Therefore, the 'self' can be viewed as a social or public construct based on the notion of the face in terms of positive social value a person claims individually. A verbal discourse, therefore, turns out to be a collective and cooperative effort or a common pursuit towards maintaining inter-personal faces. According to Goffman (2008), face management involves the avoidance process, the corrective process, the aggressive use of face work in view of the face wants and social relationships (pp. 299-310).

\section{Research Methodology}

The main aim of this paper is to study the operations of the face-saving and facethreatening mechanism involved in the dialogic discourses of characters in ASB while constructing and performing different types of identities during their dialogic interactions. In doing that social aspect of characters' occupation, authority, power, status, ethnic identity, solidarity, distance, and situational factors and how do they influence the management of face while interacting with each other are taken into account in analyzing the dialogic discourses taken from ASB. Four dialogic discourses with a diverse power structure linked to the participants' social identities have been extracted from ASB and subjected to socio-pragmatic examination and critical analytical discussion and interpretation. The analysis of each dialogic discourse is driven by the basic tenets of ICP and CDA using Goffman's (1972, 2008) framework of face management and Brown and Levinson's (1987) theory of politeness. In view of the analytical discussion, interpretations, and findings, implications on the pedagogy of literary discourses and social and interpersonal interaction have been explored, discussed and proposed.

What follows next is a socio-pragmatic analysis and discussion of characters' face management as deployed and surfaced in ASB.

\section{Socio-pragmatic analysis of identity construction and face management in the dialogic discourses from $A S B$}

Thornborrow (2005) remarks that identity, whether social, institutional or individual is something that is constantly built and negotiated all our lives during interactions with others. Identity is multidimensional for the reason that people switch roles at different times and in different contexts, which may shift into different and also sometimes conflicting identities of the people involved. The interplay of both individual and collective identities in the interaction and their face management in the following dialogue can be explored in many ways.

\section{Dialogic Discourse 1}

Turn 1: Mrs. Rupa Mehra: Who is he? Come here. Come here at once.

Turn 2: Lata: Just a friend.

Turn 3: Mrs. Rupa Mehra: Just a friend! A friend! And friends are for holding hands with? Is this what I brought you up for? ...

Turn 4: Lata: Who told you? Hema's Taiji? 
Turn 5: Mrs. Rupa Mehra: Hema's Taiji? Hema's Taiji? Is she in this too? ... She lets those girls run around all over the place with flowers in their hair in the evening. Who told me? The wretched girl asks me who told me. No one told me. It's the talk of the town, everyone knows about it. Everyone thoughtyou were a good girl with a good reputation- and now it is too late. Too late.

Turn 6: Lata: Ma, you always say Malti is such a nice girl. And she has friends like that-you know that-everyone knows that.

Turn 7: Mrs. Rupa Mehra: Be quiet! Don't answer me back! I'll give you two tight slaps. Roaming around shamelessly near the dhobi-ghat and having a gala time.

Turn 8: Lata: But Malti-

Turn 9: Mrs. Rupa Mehra: Malti! Malti! I'm talking about you, not about Malti ... Do you want to be like her? And lying to your mother. I'll never let you go for a walk again. You'll stay in this house, do you hear? Do you hear?

Turn 10: Lata: Yes, Ma ...

Turn 11: Mrs. Rupa Mehra: What's his name?

Turn 12: Lata: Kabir.

Turn 13: Mrs. Rupa Mehra: Kabir what? ... He has a name, doesn't he? What is he Kabir Lal, Kabir Mehra - or what? Are you waiting for the tea to get cold? Or have you forgotten?

Turn 14: Lata: Kabir Durrani ...

Turn 15: Mrs. Rupa Mehra: Is he a Parsi? ... A Muslim ... What did I do in my past life that I have brought this upon my beloved daughter? (ASB, pp.181-82)

Before examining the above dialogue between the mother and her daughter, it will be helpful to look at the context of the conversation. Mrs. Rupa Mehra, on her visit to a friend a day before, was reported and cautioned by her neighbor that she should be careful about her daughter as somebody saw her walking in the company of a young man holding his hand by the side of a river in the previous evening. The dialogue under examination is consequential to this alert.

The dominant force of conversation in the above dialogue is Rupa Mehra's speech act of questioning and demanding explanation from her daughter Lata about her personal relationship with the boy in question in the dialogue. Turn management in the dialogue demonstrates how the power and dominance work between the mother and daughter in the Indian socio-cultural fabric. A closer look at the turn taking and turn allocation in the dialogue suggests that Mrs. Rupa Mehra took bigger turn lengths of 217 words as compared to Lata who was allowed to take only smaller turn lengths of 37 words. Mrs. Rupa Mehra's interrogative approach (e.g. Who is he?, in turn, 1; What's his name?, in turn, 11; Is he a Parsi? in turn, 15, etc.); her imperative tone (You'll stay in this house, do you hear? In turn, 9); her interruptions (Be quiet! Don't answer me back!, in turn 7); and her aggressive treatment (Be quiet!, I'll give you two tight slaps., in turn, 7) are socio-culturally motivated choices, which display a discursive source of dominance and power of mother over her daughter. In comparison, Lata's hesitant, submissive and compliant responses (Just a friend, in turn, 2; Yes Ma..., in turn, 10, Kabir and Durrani...; in turn 14) clearly indicate that she was in a powerless position in relation to her mother. Being part of solidarity-oriented Indian society, Mrs. Rupa Mehra's strategies are the marked features of exercising authority, power and dominance over the addressee; her daughter. Mrs. Rupa Mehra is asserting her social parental identity by exercising authority to question, influence, and map out her daughter's personal relationship which might lead to marriage. Lata's well-formed submissive and complaint short responses suggest the relative formation and presentation of the identity of an obedient daughter. The communicative intentions of the mother and the corresponding submissive responses of the answer with explanation suggest that Mrs. Rupa Mehra assumes that in the capacity of the mother she has socially-sanctioned power and authority to question and demand explanations from her daughter about her personal relationship with the boy in question. On the other hand, Lata presupposes that having an inter-caste relationship without her mother's knowledge is socially at odds.

In terms of face management, Mrs. Rupa Mehra, is threatening her daughter Lata's negative face in almost every turn in the dialogue by not giving her freedom (Come here 
at once., in turn, 1); by scolding ( Is this what I brought you up for?, in turn 3) and by threatening (I'll never let you go for a walk again....; Do you hear? in turn, 9). However, Lata is trying her best to save the positive face of her mother in being submissive and respectful through her answer-clarification-explanation and compliance-oriented responses while answering to her mother's questions. Lata's submissive and compliant efforts are aimed at achieving social and familial coherence, which is influenced by two factors, which are that Lata does not want to confront her mother and she wants to maintain her due deference for her mother's socio-culturally approved parental authority to question, influence and map out her personal relationships including marriage.

\section{Dialogic Discourse 2}

Turn 1: Mrs. Rupa Mehra: No, (said Mrs. Rupa Mehra vehemently, shaking her needle for emphasis). My daughter is not going to act in any play. No. (She glared at Lata over the top of her reading glasses.) ... Boys and girls together-acting! ...

Turn 2: Lata: Like in Julius Caesar last year (ventured Lata).

Turn 3: Mrs. Rupa Mehra: You be quiet (snapped her mother). No one has asked you to speak. Have you ever heard of Savita wanting to act? To act on the stage with hundreds of people staring? And going to those nightly gatherings with boys - (ASB, pp.777-78)

Rejecting a request is considered a threat to the addressee's positive face as it violates the addressee's face want of expected approval. In this dialogue, Lata's request is bluntly rejected by her mother Mrs. Rupa Mehra (in turn 1) for performing in the annual day of her college without any mitigating effort to cover or repair the involved face threat and face loss for the addressee. However, Lata's submissive and indirect approach of persuasion (in turn 2) does not reflect any hurt feeling of losing face her mother threatened her negative face to control and deny her individual autonomy and freedom to participate in the play. On the contrary, Lata is attempting to protect and maintain her mother's positive face by avoiding confrontation and argument when her mother's view and opinion are at variance with her individual ambition and belief.

In this dialogic discourse, Mrs. Rupa Mehra and Lata hold most salient cultural identities at a higher level of generalization and abstraction. Mrs. Rupa Mehra represents the identity of a conservative mother of the early twentieth century and Lata a modern daughter of the midtwentieth century as per the timeline in the story in $A S B$. According to the established socio-cultural norms of that era, Mrs. Rupa Mehra firmly believed that Lata as a young girl of marriageable age must not be allowed to mix with a young boy to avoid her developing a negative reputation which will adversely affect her matrimonial prospects in future. Influenced by such social belief, she rejects Lata's idea of acting in a college play. Lata's indirect and polite attempt to persuade her mother to allow her to act in the play suggests that Lata testifies her mother's concerns for Lata's social reputation and it also indicates Lata's approval of her mother's socially-approved parental authority to question and to influence her children's personal decisions. Mrs. Rupa Mehra's solidarity, power, and confidence are clearly evident in her direct encroachment on the daughter's conversational space through her act of interrupting and snapping. On the other hand, Lata's attempt of mild persuasion aimed at her mother indicates her desire to act in the play to be understood and approved of. This scene in the novel suggests a generation gap and also a shift in the social attitude of modern educated Indian youth to construct their identities by asserting and exercising their personal decisions. This direction towards social change entails a change in Lata's perspective and ideology as compared to her mother's ideology of controlling young children's personal decisions and actions.

According to traditional Indian sociocultural milieu, it was a common belief that showing bold and free attitude to life and mingling of young girls with boys in public needed to be strictly discouraged in order to maintain a decent character and clean reputation. In other words, Indian culture does not encourage the concept of personal autonomy and collective solidarity is regarded as more important than individual identity and freedom. However, the opposite of this also 
stands valid for a western culture where the same conversation in countries like America or Britain is most likely to be taken as an extremely face-threatening act against the daughter, which is likely to result in a retaliatory response from the addressee. Such situations in sociolinguistic literature are considered as an example of, what Blum-Kulka and Olshtain (1984, p.196) argue, crosscultural functional variation.

\section{Dialogic Discourse 3}

Turn 1: Rasheed's father: Anyway ... why don't you have a cup of tea now that you've made such an effort to come. I'll summon Rasheed's friend, and we will talk...

Turn 2: Tiwariji: No, no- no tea, no tea. Turn 3: Rasheed's father: But we will all be having it together, Tiwariji, it is not poisoned. Even Kapoor Sahib will join us.

Turn 4: Tiwariji: He drinks tea with all of you?

Turn 5: Rasheed's father: Indeed. He eats with us too.

Turn 6:Tiwariji: ... But I have just had tea, you know, with my breakfast- I've just had tea and also far too much to eat before I left my house. Look at me. I must be careful. Your hospitality knows no bounds. But-

Turn 7: Rasheed's father: You aren't saying, by any chance, Tiwariji, are you, that what we are offering falls below your expectations? Why don't you like to eat with us? Do you think we will pollute you?

Turn 8: Tiwariji: Oh, no, no, no, it is just that an insect of the gutter like myself does not feel happy when offered the luxuries of a palace. Heh heh heh! ... (ASB, p. 659)

In this dialogue both the participants, Rasheed's father and Tiwariji, are performing face-threatening acts. Tiwariji has rejected Rasheed's father's social offer of tea and threatened the positive face of the host (turn 2). On the other hand, Rasheed's father's criticised Tiwariji's rejection of his offer which surfaces as an attack on the negative face of the addressee in not respecting the freedom of his choice (turn 3). The intended meaning in most of the conversation in this dialogue is rooted in the ethnic identities of the Tiwariji and Rasheed's father. Rasheed's Father is a Muslim and Tiwariji is an upper caste Brahmin but both are good friends. However, at the social level, the caste rules of Tiwariji do not permit him to accept to eat or drink anything offered by nonBrahmins. Tiwariji should have directly and bluntly refused to drink tea due to caste rules without any mitigating attempts to the threat to the positive face of Rasheed's father. However, as Rasheed's father held the status of Tiwariji's friend and also his power of being a wealthy landlord, Tiwariji had to mitigate his rejection of his offer of tea by giving an elaborate explanation (turn 6). Further, the use of addressee-elevating and self-lowering language by Tiwariji is aimed at minimizing the distance that has developed between them by not accepting the offer of the tea on the basis of socially determined caste rules (turn 8). Here, the guest is trying to mitigate the facethreatening situation by reducing his own image by using self-humiliating language and then glorifying the hospitality due to the solidarity of friendship and the social status of the host as a wealthy landlord.

In view of the mitigating response of the addressee Tiwariji, there is a need for an explanation with reference to social norms and the mutual authority of the conversational participants in the social context of India in the 1950 s, which is the timeframe of the story in $A S B$. The discoursal situation in this conversational exchange seems to be of an aymmetrical status. To elaborate, being a Brahmin, i.e. Tiwariji holds more social power over his non-Brahmin friend i.e. Rasheed's father. In such a social context of the relative power structure, the ameliorating explanation of Tiwariji given to his non-Brahmin Muslim addressee indicates the shifting trend in the newly independent India. The caste rules seem to be going into the melting pot and the mutual accomodation of the social status of the addressee as a friend and a wealthy landlord moving towards neutralization of rigid caste rules.

\section{Dialogic Discourse 4}

Turn 1. Ustad Majeed Khan: Malti (said Ustad Majeed Khan), carry the tanpura with respect, with both hands. It isn't the offspring of a cat. What is the matter with you? 
Turn 2. Malti: (silence; no answer.) (ASB, 1265)

This dialogic discourse is marked by the traditional relationship of a Guru (the traditional reverent concept of a teacher in the Indian socio-cultural context) and his disciple (overpolite and respectful student Malti). Ustad Majeed Khan's bitter reprimand (turn 1) uttered for Malti threatens her positive face wants of understanding and approving the addresee's individual liking and desire. Malti's music teacher's face-threatening act of bitter criticism is performed without any amelioration. The music teacher scolded the addressee for carrying the musical instrument by not using both the hands and thereby failing to treat the musical instrument with respect. Malti maintained polite silence to express her apology and also her unconditional respect for her music Guru. The Guru's angry reaction is influenced by the Indian cultural tradition to treat music as a devotional art and musical instruments as sacred. Malti's act of holding the musical instrument in a casual manner, as an offspring of a cat, was considered by Ustad Majeed Khan as an act of disrespect. Ustad Majeed Khan's face-threatening act of reprimanding was performed without any circumlocution of mitigation which is likely to sound absurd or eccentric to the readers not familiar with the socio-cultural norm of showing respect to the musical instruments in India. Misunderstanding of such speech acts by readers from the different socio-cultural background(s) may result in what Flowerdew (1988, p.77) refers to as a 'socio-pragmatic failure'.

\section{Concluding Remarks and Emerging Implications}

In the backdrop of a premise that literature is representative of human societies and human life, this paper has attempted to analyze fictional dialogic discourses from $A S B$ in the framework of Critical Discourse Analysis, Identity Construction and Performance Framework, and The sociolinguistic Face Management Theory. The analytical discussion of four dialogic excerpts from $A S B$ has been initiated and evolved on the basis of the parameters of socially-driven Power Principle and Solidarity Principle. Identity Construction and Face Management have been examined in the varied socio-cultural contexts of (a) mother and daughter's argument on the issue of freedom for young girls to develop friendship and intimacy with a boy of her choice; (b) mother and daughter's talk about the issue of the degree of social freedom for girls to avail; (c) a satirical conversation in an unequal host-guest situation constrained by caste rules, and (d) a Guru-disciple exchange of showing proper respect to the musical instrument. It becomes obvious in these situations that the conversational participants create or construct and perform their mutual identities based on the socio-cultural norms of Face Management. The explanation of face-threatening devices and strategies employed by the interlocutors in the dialogic discourses selected from $A S B$ focusses on their structure and functions and also on the individual as well as collective social factors that influenced their use in specific ways. Based on the analytical discussion, it can be claimed that the character utterances in the ASB prove to be sensitive to the social and cultural contexts in which they are used in accordance with the subjective experiences and value system of the conversational participants. It will not be an exaggeration to claim that the whole gamut of inter-personal communicative discourse is mostly influenced by socio-pragmatic factors and considerations. Thus, based on the main tenets of CDA proposed by Fairclough and Wodak (1997, pp. 271-280), it can be concluded that discourse constitutes society and culture; power relations are discursive; the link between text and society is mediated; discourse analysis is interpretative and explanatory; and discourse is a form of social action.

In view of the above analytical findings, it can be strongly argued that the real significance and meanings in the Indian English Fiction or Fictional works from other socio-cultural contexts cannot be studied, discussed and appreciated without an in-depth knowledge and understanding of the real social and cultural issues that are involved and integrated into these discourses. This leads to a pedagogical recommendation of developing the context-bound textual, linguistic, and cultural competence in students who study literature in order to prepare them to understand, study and evaluate the patterns of discourse in their right perspectives. Using House and Kasper's (1981, p.184) argument that pragmatic aspects of communication, such as politeness markers, are inseparable parts of the foreign cultural 
system and therefore they should not be borrowed and used as it is and be interpreted by reference to one's native socio-cultural framework. Put another way, an attempt should be made to minimize interference of the native culture in order to prevent ineffective, inappropriate and possibly impolite interpretations of character utterances in the novel or drama. Socio-pragmatic interpretations of literary discourses will not only sensitize but also raise the students' awareness of discourse patterns of real-life communication. Furthermore, it may also provide a valid testing ground for the discourse models themselves and also the students will derive a stimulating learning experience through such analytical attempts.

\section{Acknowledgements}

I wish to acknowledge that this paper drew heavily on the materials and facilities available at the English Language Center, Nizwa College of Technology. I offer my sincere thanks to Mr. Sultan Al-Dighaishi, HoD, ELC, NCT for his constant encouragement and support. This note of thanksgiving would be insincere if I fail to appreciate the great help that I received from Mrs. Lalitha Justin, Lecturer, ELC, NCT.

\section{References}

Brown, P. \& Levinson, S. C. (1987). Politeness: Some universals in language usage. Cambridge: Cambridge University Press.

Blum-Kulka, S. \& Olshtain, (1984). Requests and apologies: A cross-cultural study of speech act realization patterns (CCSSARP). Applied Linguistics, 5, (3), 196213.

Fairclough, N. (1993). Language and power. New York: Longman.

Fairclough, N. \& Wodak, R. (1997). Critical discourse analysis. In T. van Dijk (Ed.), Discourse studies: A multidisciplinary introduction, 2, (pp. 258-284). London: Sage.
Flowerdew, J. (1988). Speech acts and language teaching. Language Teaching, 21 (2), 69-82.

Goffman, E. (1972). On face work: An analysis of ritual elements in social interaction. In J. L. Morgan (Eds.), Syntax and Semantics, 3, Speech Acts (pp. 319-346), New York: Academic Press.

Goffman, E. (2008). On face-work: An analysis of ritual elements in social interaction. In Adam Jawoski \& Nikolas Coupland (Eds.) The Discourse Reader, 2nd Edn., (pp. 299310). Oxon: Routledge.

Gumperz, J. J. \& Gumperz, J. C. (1997). Introduction: Language and the communication of social identity. In J. J. Gumperz (Ed.), Language and Social Identity (pp. 1-21). Cambridge: Cambridge University Press

House, J. \& Kasper, G. (1981). Politeness markers in English and German. In F. Coulmus (Ed.), Conversational Routine, 2 (pp.157 - 185). The Hague, The Netherlands: Mouton Publishers.

Seth, V. (1993, rep. 2001) A Suitable Boy. New Delhi: Penguin Books.

Teun, A. \& Dijk, V. (2010). Critical discourse analysis. In Deborah Shiffrin, Deborah Tannen \& Heidi E. Hamilton (Eds.), The Handbook of Discourse Analysis (pp. 352371). New Jersey: Blackwell Publishing Ltd.

Thornborrow, J. (2005). Language and identity. In I. Singh and J.S. Peccei (eds.), Language, Society, and Power: An Introduction (pp.158-172). London: Routledge.

Watson, C. (2006). Narratives of practice and the construction of identity in teaching. Teachers and Teaching: Theory and Practice, 12 (5), 509-526.

Wodak, R. (2000). Does sociolinguistics need social theory? Social perspectives on critical discourse analysis. Discourse and Society, 2 (3), 123-147. 